\title{
Should we consider blocking the inhibitory immune checkpoint molecules for treating T cell exhaustion in sepsis?
}

\author{
Manu Shankar-Hari ${ }^{1,2^{*}}$ (B), Matthew Fish ${ }^{1}$ and Elie Azoulay ${ }^{3,4}$
}

(C) 2019 Springer-Verlag GmbH Germany, part of Springer Nature

Sepsis is defined as life-threatening organ dysfunction caused by dysregulated host responses to infection [1]. These dysregulated host responses involve the immune system and other organ systems, manifesting as organ dysfunction [1]. The dysregulated immune responses in sepsis affect both the innate and the adaptive immune systems. There is immune activation alongside functional impairment of innate and adaptive immune cells [2]. One aspect of adaptive immune system changes that contributes towards sepsis-related immunosuppression is impaired lymphocyte function, alongside accelerated lymphocyte loss [2]. The reason being, in health, activated $C D 4+$ helper $T$ cells secrete an array of cytokines and chemokines to recruit innate immune cells to sites of infection, enhance their microbicidal activity, help B lymphocyte class switch to make antibodies and generate long-lived lymphocyte memory [3]. Another unique property of $\mathrm{CD} 4+$ helper $\mathrm{T}$ cells is that they can initiate a cellular programme to polarise towards a particular subset, based on the danger signals they sense [4]. In sepsis, there is a polarisation towards $T$ helper- 2 subsets [5].

$\mathrm{T}$ cell exhaustion is defined by three features [6]. First, exhausted $\mathrm{T}$ cells have impaired effector function. An example of impaired effector function is the inability to respond to ex vivo antigen challenge with the normal array of cytokines, in sepsis [7]. Second, there is a sustained and increased expression of inhibitory immune checkpoint molecules on exhausted $\mathrm{T}$ cell surface. For example, increased expression of programmed cell

*Correspondence: manu.shankar-hari@kcl.ac.uk

1 Present Address: School of Immunology and Microbial Sciences, King's College London, 5th Floor, Southwark Wing, London SE1 9RT, UK

Full author information is available at the end of the article death-1 (PD-1) receptor and its ligand (PD-L1) [2] is seen in patients with infection [8] and in sepsis [2,9]. Importantly, PD-1 is neither the only nor the essential inhibitory checkpoint molecule associated with $\mathrm{T}$ cell exhaustion. Third, exhausted $\mathrm{T}$ cells have a distinct transcriptional state that impairs development and persistence of highly functional T cell memory [6]. Altered transcriptional state on exhausted $\mathrm{T}$ cells have not been characterised in bacterial sepsis, but have been well characterised in patients with viral infections with high viral load and in cancer biology [6]. In ex vivo experiments on lymphocytes from patients with sepsis, blocking PD-1 or PD-L1 using antibodies, reduced accelerated lymphocyte apoptosis and recovered some immune cell effector function [10], which varied with different immunoadjuvants with recombinant interleukin-7 (IL-7) showing maximum response [9]. There is limited evidence from sepsis studies that impaired lymphocyte effector function results in increased nosocomial infection risk and that this risk could be reversed by reversing lymphocyte dysfunction with PD-1 blockade.

Based on these observations, Hotchkiss and colleagues generated the hypothesis that antibody-mediated immunotherapy by blocking PD-1 or PD-L1 may reverse T cell exhaustion-mediated immunosuppression in critically ill patients with sepsis (Fig. 1) [2]. It is acknowledged that critically ill patients, especially those patients with sepsis have significant alterations in pharmacokinetics and pharmacodynamics, resulting from organ dysfunction and acute alterations in volume of distribution of drugs. Furthermore, cancer patients receiving anti-PD-1 treatments have an increase in organ-specific adverse events such as hypothyroidism, pneumonitis, and hypophysitis [11]. Thus, there is a need for well-designed early-phase

\section{Springer}




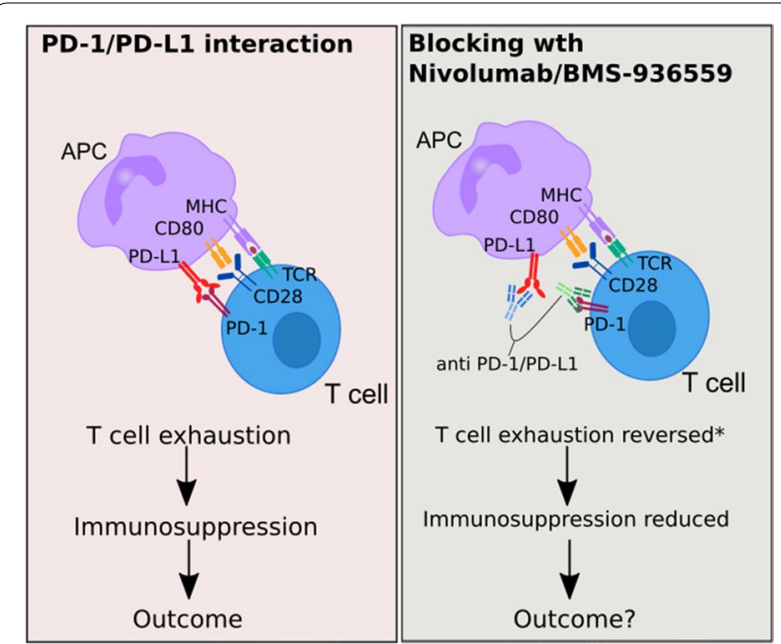

Fig. 1 Role of PD-1 and PD-L1 in T cell exhaustion and potential for treatment. $A P C$ antigen presenting cell, $P D-1=$ programmed cell death-1; $P D-L 1$ programmed cell death ligand-1, CD cluster of differentiation, TCRT cell receptor; anti-PD-1 and anti-PD-L1 are monoclonal antibodies to corresponding receptors; *there is no evidence whether blocking one inhibitory check point molecule like PD-1

reverses T cell exhaustion in sepsis; outcome? refers to uncertainty on patient-centred outcomes; BMS-936559 is anti-PD-L1 antibody tested in a previous trial [13]

trials to explore the pharmacokinetics and pharmacodynamics of passive anti-PD-1 or anti-PD-L1 monoclonal antibody immunotherapy, prior to later phase trials on patient-centred endpoints.

In a recent issue of the journal, Hotchkiss and colleagues report a phase-1b parallel group randomised controlled trial of anti-PD-1 monoclonal antibody (nivolumab) in 31 adult patients with sepsis and total lymphopenia (defined as absolute lymphocyte counts $\leq 1.1 \times 10^{3}$ cells/microlitre) [12]. There was no placebo arm in this phase- $1 \mathrm{~b}$ trial. The parallel groups to assess pharmacokinetics and pharmacodynamics were two different doses of nivolumab $480 \mathrm{mg}$ and $960 \mathrm{mg}$. This trial shows that in sepsis patients, nivolumab has a greater volume of distribution, more rapid clearance, and shorter half-life, when compared to published data from cancer patients. Pharmacodynamic assessments highlighted that both doses had greater than 90\% PD-1 receptor occupancy at 28 days, similar recovery of human leukocyte antigen-DR expression on monocytes, and similar recovery in absolute lymphocyte counts. When using anti-immune checkpoint inhibitor therapy, two immunological side effects to be considered is an exaggerated cytokine response and higher risk of autoimmunity. There were no major differences in the representative pro-inflammatory cytokines (IL-6, IL-8, tumour necrosis factor) and anti-inflammatory cytokines (IL-10). Autoimmunity was not directly assessed in the trial but was not apparent clinically, in contrast to observations in cancer patients. Encouragingly, there were no unexpected adverse events or serious adverse events with nivolumab in this critically ill adult sepsis population.

This trial must be considered alongside a recent phase$1 \mathrm{~b}$ placebo controlled escalating dose-randomised controlled trial assessing pharmacokinetics and pharmacodynamics of anti-PD-LI monoclonal antibody (BMS-936559) in 24 adult patients with similar eligibility criteria [13]. In sepsis patients, BMS-936559 also had higher volumes of distribution and faster elimination rates. The receptor occupancy of $>80 \%$ was achieved at a dose of $900 \mathrm{mg}$ with BMS-936559. In contrast, the receptor occupancy was greater than $90 \%$ even with the lower nivolumab dose of $480 \mathrm{mg}$, which may be relevant, as it potentially lowers the risk of exaggerated cytokine response and autoimmunity in later phase trials.

Another intervention aimed at restoring lymphocyte count and function tested recently with a phase- $2 \mathrm{~b}$ placebo controlled, double-blind, 3-arm randomised controlled trial in 24 sepsis patients with severe lymphopenia (defined as absolute lymphocyte counts $\leq 0.9 \times 10^{3}$ cells/ microlitre), was recombinant human IL-7 (CYT107) [14]. The marked loss of CD4+ and CD8+ immune effector cells was reversed and activation markers of CD4 T cells were increased by CYT107, implying improvement of impaired lymphocyte function in sepsis patients.

What next steps do these trials highlight? First, $\mathrm{T}$ cell exhaustion needs to be defined in the context of sepsis. Second, do these interventions reverse $\mathrm{T}$ cell exhaustion in sepsis. Third, we may need to consider whether monoclonal immune checkpoint inhibitors antibodies should be co-administered with recombinant IL-7 to improve lymphocyte counts. Fourth, lymphopenia is potentially feasible enrichment marker for immunomodulation trials in sepsis patients and the authors have considered it as marker for immunosuppression and prognostic enrichment [15]. The relationship between lymphopenia and $\mathrm{T}$ cell exhaustion in sepsis needs evaluation. We need to understand the magnitude and duration of lymphopenia reversal required to achieve benefit in sepsis patients for designing later phase trials. The risk of autoimmunity with these treatments must be studied using longer term follow-up of sepsis patients with biological measurements.

\footnotetext{
Author details

${ }^{1}$ Present Address: School of Immunology and Microbial Sciences, King's College London, 5th Floor, Southwark Wing, London SE1 9RT, UK. ${ }^{2}$ Guy's and St Thomas' NHS Foundation Trust, ICU Support Offices, 1st Floor, East Wing, St Thomas' Hospital, London SE1 7EH, UK. ${ }^{3}$ University of Paris-Diderot, Sorbonne
} 
Paris-Cité, Paris, France. ${ }^{4}$ Faculty of Medicine at the Saint Louis Hospital, Paris, France.

\section{Author contributions}

All the authors developed the outline. MSH wrote the first draft. All the authors contributed to the critical revision of the manuscript for important intellectual content.

\section{Funding}

Dr Shankar-Hari is supported by the National Institute for Health Research Clinician Scientist Award (CS-2016-16-011). The views expressed in this publication are those of the author(s) and not necessarily those of the NHS, the National Institute for Health Research or the Department of Health and social care. Mr Fish is supported by the National Institute of Academic Anaesthesia BJA-RCOA Ph.D. Fellowship.

\section{Compliance with ethical standards}

\section{Conflicts of interest}

MS-H is on the Editorial Board for ICM and declares no competing interests. MF declares no competing interests. Dr. Azoulay has received fees for lectures from Pfizer, Alexion, Gilead and MSD.

\section{Publisher's Note}

Springer Nature remains neutral with regard to jurisdictional claims in published maps and institutional affiliations.

Received: 26 September 2019 Accepted: 27 September 2019 Published online: 28 October 2019

\section{References}

1. Singer M, Deutschman CS, Seymour CW, Shankar-Hari M, Annane D, Bauer M, Bellomo R, Bernard GR, Chiche JD, Coopersmith CM, Hotchkiss RS, Levy MM, Marshall JC, Martin GS, Opal SM, Rubenfeld GD, van der Poll T, Vincent JL, Angus DC (2016) The third international consensus definitions for sepsis and septic shock (sepsis-3). JAMA 315:801-810

2. van der Poll T, van de Veerdonk FL, Scicluna BP, Netea MG (2017) The immunopathology of sepsis and potential therapeutic targets. Nat Rev Immunol 17:407-420

3. van den Broek T, Borghans JAM, van Wijk F (2018) The full spectrum of human naive T cells. Nat Rev Immunol 18:363-373

4. DuPage M, Bluestone JA (2016) Harnessing the plasticity of CD4(+) T cells to treat immune-mediated disease. Nat Rev Immunol 16:149-163
5. Ferguson NR, Galley HF, Webster NR (1999) Thelper cell subset ratios in patients with severe sepsis. Intensive Care Med 25:106-109

6. Wherry EJ, Kurachi M (2015) Molecular and cellular insights into T cell exhaustion. Nat Rev Immunol 15:486-499

7. Boomer JS, To K, Chang KC, Takasu O, Osborne DF, Walton AH, Bricker TL, Jarman SD 2nd, Kreisel D, Krupnick AS, Srivastava A, Swanson PE, Green JM, Hotchkiss RS (2011) Immunosuppression in patients who die of sepsis and multiple organ failure. JAMA 306:2594-2605

8. Shankar-Hari M, Datta D, Wilson J, Assi V, Stephen J, Weir CJ, Rennie J, Antonelli J, Bateman A, Felton JM, Warner N, Judge K, Keenan J, Wang A, Burpee T, Brown AK, Lewis SM, Mare T, Roy Al, Wright J, Hulme G, Dimmick I, Gray A, Rossi AG, Simpson AJ, Conway Morris A, Walsh TS (2018) Early PREdiction of sepsis using leukocyte surface biomarkers: the ExPRESsepsis cohort study. Intensive Care Med 44:1836-1848

9. Thampy LK, Remy KE, Walton AH, Hong Z, Liu K, Liu R, Yi V, Burnham CD, Hotchkiss RS (2018) Restoration of T cell function in multi-drug resistant bacterial sepsis after interleukin-7, anti-PD-L1, and OX-40 administration. PLoS One 13:e0199497

10. Patera AC, Drewry AM, Chang K, Beiter ER, Osborne D, Hotchkiss RS (2016) Frontline science: defects in immune function in patients with sepsis are associated with PD-1 or PD-L1 expression and can be restored by antibodies targeting PD-1 or PD-L1. J Leukoc Biol 100:1239-1254

11. Baxi S, Yang A, Gennarelli RL, Khan N, Wang Z, Boyce L, Korenstein D (2018) Immune-related adverse events for anti-PD-1 and anti-PD-L1 drugs: systematic review and meta-analysis. BMJ 360:k793

12. Hotchkiss RS, Colston E, Yende S et al (2019) Immune checkpoint inhibition in sepsis: a Phase $1 \mathrm{~b}$ randomized study to evaluate the safety, tolerability, pharmacokinetics, and pharmacodynamics of nivolumab. Intensive Care Med 45(10):1360-1371

13. Hotchkiss RS, Colston E, Yende S, Angus DC, Moldawer LL, Crouser ED, Martin GS, Coopersmith CM, Brakenridge S, Mayr FB, Park PK, Ye J, Catlett IM, Girgis IG, Grasela DM (2019) Immune checkpoint inhibition in sepsis: a phase $1 \mathrm{~b}$ randomized, placebo-controlled, single ascending dose study of antiprogrammed cell death-ligand 1 antibody (BMS-936559). Crit Care Med 47:632-642

14. Francois $B$, Jeannet $R$, Daix T, Walton $A H$, Shotwell MS, Unsinger J, Monneret G, Rimmele T, Blood T, Morre M, Gregoire A, Mayo GA, Blood J, Durum SK, Sherwood ER, Hotchkiss RS (2018) Interleukin-7 restores lymphocytes in septic shock: the IRIS-7 randomized clinical trial. JCI Insight. https://doi.org/10.1172/jci.insight.98960

15. Shankar-Hari M, Rubenfeld GD (2019) Population enrichment for critical care trials: phenotypes and differential outcomes. Curr Opin Crit Care 25:489-497 